\title{
Application of layout optimization to the design of additively manufactured metallic components
}

\author{
Christopher J. Smith ${ }^{1,2} \cdot$ Matthew Gilbert ${ }^{1} \cdot$ Iain Todd $^{2} \cdot$ Fatos Derguti $^{3}$
}

Received: 18 December 2014 / Revised: 21 January 2016 / Accepted: 27 January 2016 / Published online: 20 April 2016

(C) The Author(s) 2016. This article is published with open access at Springerlink.com

\begin{abstract}
Additive manufacturing ('3D printing') techniques provide engineers with unprecedented design freedoms, opening up the possibility for stronger and lighter component designs. In this paper 'layout optimization' is used to provide a reference volume and to identify potential design topologies for a given component, providing a useful alternative to continuum based topology optimization approaches (which normally require labour intensive post-processing in order to realise a practical component). Here simple rules are used to automatically transform a line structure layout into a 3D continuum. Two examples are considered: (i) a simple beam component subject to three-point bending; (ii) a more complex air-brake hinge component, designed for the Bloodhound supersonic car. These components were successfully additively manufactured using titanium Ti-6Al-4V, using the Electron Beam Melting (EBM) process. Also, to verify the efficacy of the process and the mechanical performance of the fabricated
\end{abstract}

Matthew Gilbert

m.gilbert@sheffield.ac.uk

Christopher J. Smith

chrisjsmith@sheffield.ac.uk

Iain Todd

i.todd@sheffield.ac.uk

Fatos Derguti

fatos.derguti@gmail.com

1 Department Civil \& Structural Engineering, University of Sheffield, Mappin Street, Sheffield, S1 3JD, UK

2 Department Materials Science \& Engineering, University of Sheffield, Mappin Street, Sheffield, S1 3JD, UK

3 3T RPD Ltd, Fulton Court, Wofford Way, Greenham Business Park, Newbury RG19 6HD, UK specimens, a total of 12 beam samples were load tested to failure, demonstrating that the target design load could successfully be met.

Keywords Layout optimization · Topology optimization · Additive manufacture $\cdot$ EBM $\cdot$ 3D Printing

\section{Introduction}

Additive manufacturing ('3D printing') techniques have matured rapidly in recent years, and are now starting to deliver on their promise of providing engineers with unprecedented design freedoms. However, to date there has been a limited range of tools available to engineers wishing to exploit these freedoms, with the result that many components produced using additive manufacturing techniques have had similar forms to those produced using conventional manufacturing methods (e.g. casting or machining). When strong and light components are required, structural optimization techniques have the potential to address this.

To date the predominant structural optimization technique applied to component design has been continuum topology optimization (see e.g. Deaton and Grandhi (2014)). For example, the Solid Isotropic Material with Penalization (SIMP) method has been implemented in a number of commercial FE-based packages, e.g. OptiStruct, Ansys, etc. (Rozvany 2009). As a result SIMP is now used as a design tool in many industries, particularly the aerospace and automotive industries, for example by Ford (Wieloch and Taslim 2004) and EADS (Tomlin and Meyer 2011). Although the application of continuum topology optimization techniques to the design of additively manufactured components is described in a number of papers in the literature, frequently researchers have stopped short of 
fabricating the designs (e.g. Brackett et al. 2011, Aremu et al. 2010), or, if fabricated, have not undertaken load testing (e.g. Razaie et al. 2013). However, in the study described by Cansizoglu et al. (2008), additively manufactured designs were load tested, though it was found that the load test results did not completely match predictions. Another important issue is that although the solutions obtained using SIMP and other comparable continuum topology optimization techniques comprise continua, as pointed out by Deaton and Grandhi (2014), the solutions obtained are often only suitable for conceptual design purposes, and significant manual post-processing of the final solution is normally required in order to obtain a viable design solution; to address this new formulations capable of obtaining solutions which are closer to the final design are being actively investigated (e.g. Guo et al. 2014). Here the potential for 'layout optimization' to be used instead of continuum based methods is explored. A workflow is proposed which includes automatic transformation of the normal 'line structure' output from the layout optimization procedure into a continuum.

Numerical layout optimization, first proposed by Dorn et al. (1964), can now be used to obtain extremely accurate solutions, which can be, in the case of $2 \mathrm{D}$ problems, almost identical to exact analytical solutions (e.g. see Gilbert and Tyas 2003; Sokół and Lewiński 2010; Pichugin et al. 2012). These can serve as reference solutions for use in later stages of the design process. However, the forms of the truss structures which are identified can appear very impractical. This is because these typically contain numerous joints and interconnecting elements, which would be prohibitively expensive to fabricate using conventional manufacturing techniques. However, the practicality of the solutions obtained using layout optimization can be viewed in a new light when using additive manufacturing, because complex forms can often be fabricated without difficulty. Additionally, a layout optimization based approach can be expected to be particularly useful for scenarios where the final component occupies only a small percentage of the permitted design space, situations where continuum based alternatives appear less well-suited (e.g. $10 \%$ is the minimum volume fraction allowed in the continuum based optimization software recently described by Aage et al. (2013)).

In this paper details of a layout optimization based design workflow will be outlined. The main steps in the work-low are summarized below:

1. Determine a reference volume, $V_{0}$, for the component in question by performing one or more high resolution layout optimization runs, taking account of the extent of the design domain and the loads and boundary conditions, but no account of 'practical' constraints.
2. Determine a practical layout by performing further layout optimization runs (these may involve runs with various practical constraints included, or simply the use of lower nodal resolutions if fewer elements are required in the final design).

3. Perform post-processing steps as necessary (e.g. impose minimum area or buckling / overall stability constraints, if not explicitly enforced in step 2), to obtain an updated design and associated volume $V$.

4. Check structural efficiency $e=V_{0} / V$. Repeat from step 2 if efficiency $e$ is below an acceptable threshold.

5. Obtain a continuum model by converting the linestructure using geometrical rules. (Recheck structural efficiency if desired.)

The specific layout optimization and other techniques used in the above workflow can be sophisticated or, as in the present study, purposely simple. A more detailed view of the workflow is shown in Fig. 1. The final CAD model can be analysed further (e.g. in a commercial FE package) or additively manufactured directly. The layout optimization stage is described in more detail in Section 2 whilst the various post-processing steps required are outlined in Section 3. The workflow is then applied to the design of a simple and a somewhat more complex component (Section 4), which are then fabricated using the electron beam melting (EBM) additive manufacturing technology and, in the case of the simpler component, load-tested to failure (Section 5).

\section{Layout optimization}

\subsection{Basic formulation}

Numerical layout optimization provides a powerful and efficient means of identifying the optimum topology of discrete truss structures. For a given set of load cases and support conditions, layout optimization can be used to determine a minimum volume truss topology; here the objective will be to optimize components for strength. With the basic single load case 'plastic' formulation (Dorn et al. 1964) the resulting structure will be fully stressed when the design load is applied; the design solution obtained will also be the same as the topology derived using the minimum compliance truss formulation. However, for practical problems the use of multiple load cases is often necessary to ensure robustness.

Layout optimization is based on the ground structure approach, in which nodes distributed across the design space are interconnected by potential members (or 'truss bars'). Various formulations are possible; here each member is assumed to have two variables associated with it: force and cross-sectional area. The objective of the optimization is to minimize the total structural volume, subject to 


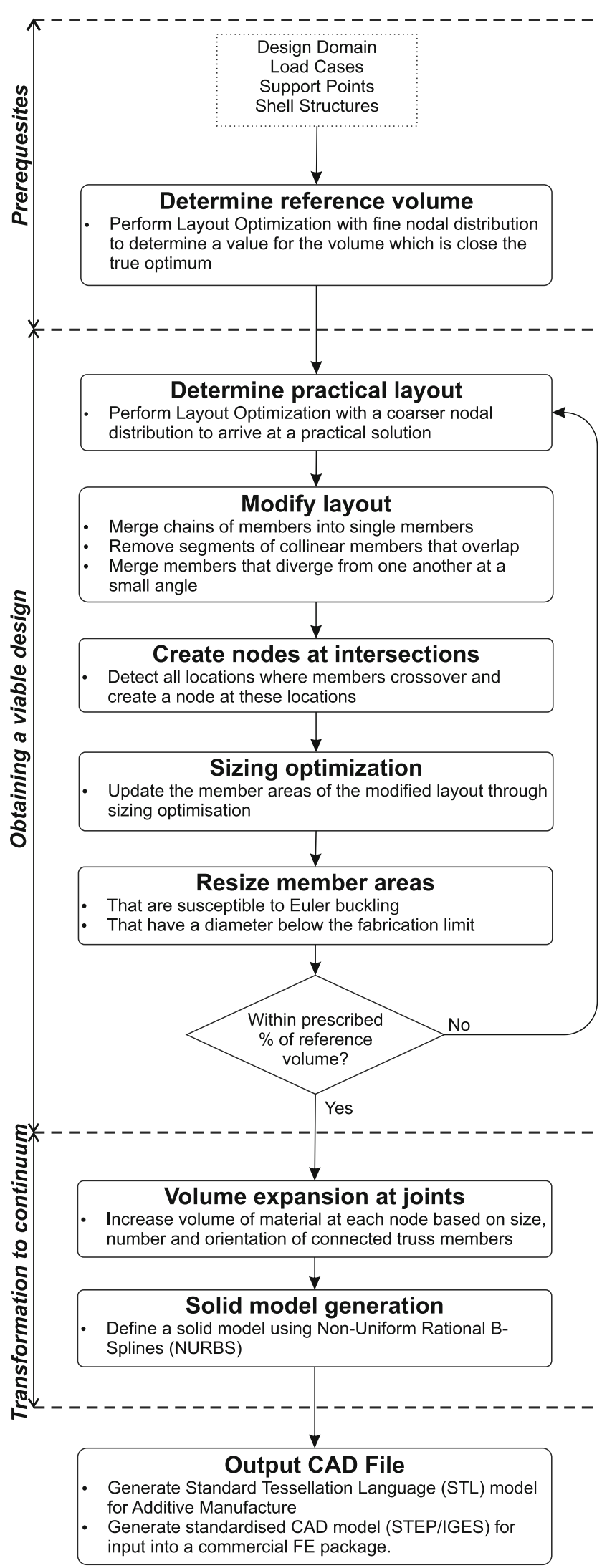

Fig. 1 Flow chart showing the proposed design workflow, from layout optimization to finalized CAD model equilibrium constraints and constraints which ensure that the cross-sectional area of each member is sufficient, given the forces across all load cases to be sustained and the tensile and compressive strength of the material:

$\min V=\mathbf{l}^{\mathrm{T}} \mathbf{a}$

subject to

$\mathbf{B} \mathbf{q}^{\alpha}=\mathbf{f}^{\alpha}$

$\left.\begin{array}{l}a_{i} \geq q_{i}^{\alpha} / \sigma^{+} \\ a_{i} \geq-q_{i}^{\alpha} / \sigma^{-}\end{array}\right\} \quad \begin{aligned} & i=1, \ldots, m \\ & \alpha=1, \ldots, p\end{aligned}$

where $V$ is the total volume of the structure; $\mathbf{l}$ is a vector of individual member lengths, $\mathbf{I}^{\mathrm{T}}=\left\{l_{1}, l_{2}, \ldots l_{m}\right\}$, where $l_{i}$ is the length of member $i(i=1, \ldots, m)$, $\mathbf{a}$ is a vector of member cross-sectional areas, $\mathbf{a}^{\mathrm{T}}=\left\{a_{1}, a_{2}, \ldots, a_{m}\right\}$, where $a_{i}$ is the cross-sectional area of member $i(i=1, \ldots, m)$. Also, $\mathbf{B}$ is a suitable $(3 n \times m)$ equilibrium matrix containing direction cosines; $\mathbf{q}$ is a vector of member axial forces, $\mathbf{q}^{\mathrm{T}}=\left\{q_{1}, q_{2}, \ldots, q_{m}\right\}$, where $q_{i}$ is the force in member $i$ $(i=1, \ldots, m) ; \mathbf{f}^{\alpha}$ is a vector of applied loads and load cases, where $\alpha$ represents an individual load case $(\alpha=1, \ldots, p)$ and $\mathbf{f}^{\alpha \mathrm{T}}=\left\{f_{1}^{x}, f_{1}^{y}, f_{1}^{z}, f_{2}^{x}, f_{2}^{y}, f_{2}^{z}, \ldots, f_{m}^{z}\right\}^{\alpha}$ where $f_{j}^{x}$, $f_{j}^{y}, f_{j}^{z}$ are the $x, y$ and $z$ direction components of the live load applied to node $j(j=1, \ldots, n)$. Finally, $\sigma^{+}$and $\sigma^{-}$ are respectively the limiting tensile and compressive stresses that can be sustained by the material. This type of problem can be solved using linear programming (LP). Note that kinematic compatibility constraints are not required in the plastic formulation, even when multiple load cases are involved. This is because plastic yielding of members can occur, allowing forces within the structure to redistribute as necessary. Theoretical issues associated with the plastic multiple load case formulation are considered in more depth by Rozvany et al. (2014).

However, the use of a fully connected ground structure becomes computationally expensive for large-scale problems. This is because as the number of nodes $n$ in a problem grows, the number of potential members quickly becomes large (since there will be $n(n-1) / 2$ connections in a fully connected ground structure). As the majority of potential members will not be represented in the final design (i.e. will have zero area), representing all potential members becomes rather inefficient. To address this, the method originally developed by Gilbert and Tyas (2003) can be used. This method involves starting with a comparatively sparse ground structure (e.g. with only adjacent nodes interconnected) and then adaptively adding additional potential members in an iterative solution procedure. The Michell-Hemp optimality criteria (which imposes limits on the virtual strain $\epsilon_{i}$ which can be experienced by each 
potential member $i$ ), is used to judge whether to admit additional members to the ground structure:

$-\frac{1}{\sigma_{0}} \leq \epsilon_{i} \leq \frac{1}{\sigma_{0}}, \quad i=1, \ldots, m$

Where $\sigma_{0}$ is the limiting material stress. The virtual strain can easily be calculated from nodal values in the dual LP problem and, to ensure the problem size does not grow too rapidly, only members most violating the above criteria are added initially in the procedure (Gilbert and Tyas 2003). The procedure terminates when no potential members violate the criteria, ensuring that the solution obtained is the same as would have been obtained using a fully connected ground structure. The procedure was extended to allow multiple load cases and unequal limiting tensile and compressive stresses to be handled by Pritchard et al. (2005). The latter formulation has been programmed in a $\mathrm{C}++$ based optimization tool developed at the University of Sheffield and the Mosek (2014) interior point linear programming library is used to obtain solutions.

\subsection{Including rigid shell structures}

In addition to truss bar members, rigid shell structures can also be included to facilitate the modelling of more realistic scenarios. For example, a component to be optimized will often have to integrate into a larger assembly of components, and to model component interfaces rigid shell structures can conveniently be employed (e.g. in the case of the simple beam problem that will be considered in this paper, a rigid shell structure is used to model the region where the load is to be applied by the universal testing machine).

Triangular elements are used to form the rigid shell structure in this formulation, with the locations of these prescribed prior to the optimization (Fig. 2). For simplicity, a single connection point is created at the centroid of each triangular element forming the rigid shell structure, which can accept multiple truss connections as well as the application of external forces. Equilibrium needs only to be considered at a single master node, with the equilibrium matrix for a single element ' $i$ ' shown in (3). Here $v_{i}$ is the vector $\left[v_{i, x}, v_{i, y}, v_{i, z}\right]$ of element ' $i$ ', $d_{i}$ is the vector between the connection node of element ' $i$ ' to the shell and the master node, and $l_{i}$ is the length of element ' $i$ '.

$$
\left[\begin{array}{c}
\frac{v_{i, x}}{l_{i}} \\
\frac{v_{i, y}}{l_{i}} \\
\frac{v_{i, z}}{l_{i}} \\
\frac{v_{i, x}}{l_{i}}\left(d_{i, y}+d_{i, z}\right) \\
\frac{V_{i, y}}{l_{i}}\left(d_{i, x}+d_{i, z}\right) \\
\frac{v_{i, z}}{l_{i}}\left(d_{i, x}+d_{i, y}\right)
\end{array}\right]\left[q_{i}\right]=\left[\begin{array}{c}
F_{s, x} \\
F_{s, y} \\
F_{s, z} \\
M_{s, x} \\
M_{s, y} \\
M_{s, z}
\end{array}\right]
$$

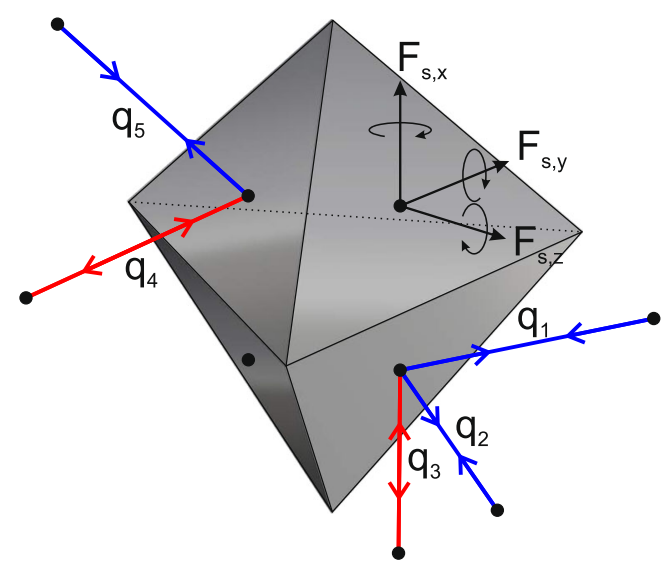

Fig. 2 Member forces and applied external forces and moments acting on a rigid shell structure are resolved at a single node

The global equilibrium of each rigid shell structure is then enforced, so that equilibrium equation (1b) is rewritten as:

$$
\left[\begin{array}{c}
\mathbf{B} \\
\mathbf{B}_{s}
\end{array}\right]\left[\mathbf{q}^{\alpha}\right]=\left[\begin{array}{l}
\mathbf{f}^{\alpha} \\
\mathbf{f}_{s}^{\alpha}
\end{array}\right]
$$

Where $\mathbf{B}_{\mathbf{s}}$ is the equilibrium matrix collecting terms for each rigid shell structure, and where $\mathbf{f}_{\mathbf{s}}$ collects external forces $\left(F_{S}\right)$ and moments $\left(M_{S}\right)$ applied to each rigid shell structure.

\subsection{Determining a reference truss volume and a practical layout}

It has been found that modern numerical layout optimization techniques can provide very good estimates of the exact analytical solution, often well within $1 \%$ of the latter in the case of two-dimensional problems (e.g. Darwich et al 2010, Sokół and Lewiński 2010). Although the corresponding truss layouts cannot be manufactured directly, due to the high number of members that are usually involved, they do provide a useful reference volume. When attempting to yield a practical solution various rationalization techniques can be applied (e.g. He and Gilbert 2015), or alternatively, the optimization can simply be performed with a coarse nodal discretization and, provided the layout obtained is practical, and the associated volume lies within an acceptable percentage of the reference volume, then it can be deemed acceptable. For this initial investigation any solution that fell within $20 \%$ of the reference volume was deemed to be potentially acceptable. 


\section{Transformation of line structure to a continuum}

The output from the layout optimization procedure will be a frame comprising a series of one-dimensional line elements. In order for this to be realized physically, it must be transformed into a three-dimensional continuum. Various means of achieving this are possible; here the emphasis has been on simplicity and ease of implementation. Should the basic approach prove to be attractive then clearly the level of sophistication can in due course be increased.

Thus, for sake of simplicity, it was decided that each line element would be transformed into a solid circular element (i.e a simple cylinder). Steps must be taken to address situations where two or more members, once expanded, occupy some of the same volume. This can occur in the vicinity of joints and in regions where members overlap. Also, at this stage, members which are too thin to be effectively fabricated using the chosen additive manufacturing process, or which are susceptible to buckling, need to be resized. These stages, together with the final form generation, constitute steps in the post-processing workflow, which will now be outlined in sequence.

\subsection{Modify layout}

\subsubsection{Collinearity}

Chains of collinear elements, of the sort shown between nodes A and B in Fig. 3a, should be identified and then merged. This is primarily because the simple buckling analysis described in Section 3.4 requires these to be merged into a single element. This can be achieved by searching for nodes that have only two connections (with the same normalized direction vector), and then eliminating them (i.e. nodes C, D and E in Fig. 3a).

A collinear member that overlaps with a section of, or the entirety of, another member must also be identified and modified (e.g. see Fig. 3b, where member AB overlaps with member $\mathrm{CD}$ ). (Otherwise, when the line elements are converted to cylinders, there will be significant overlap which, if left unchecked, will result in high local stresses.) Considering the example shown in Fig. 3b, (5a) can be used to identify members that are collinear and (5b) and (5c) can be used to identify if these collinear members pass through an end node of another member, and hence overlap.

$$
\begin{aligned}
& \left|\frac{(i \cdot j)\left(i \cdot v_{A C}\right)}{|i|^{2}|j|\left|v_{A C}\right|}\right|=1 \\
& 0<\frac{v_{A C}, v_{A D}}{i}<1 \\
& 0<\frac{v_{C A}, v_{C B}}{j}<1
\end{aligned}
$$

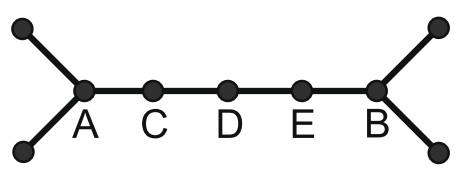

a

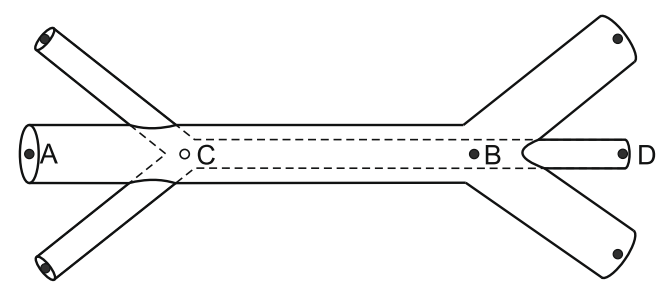

b

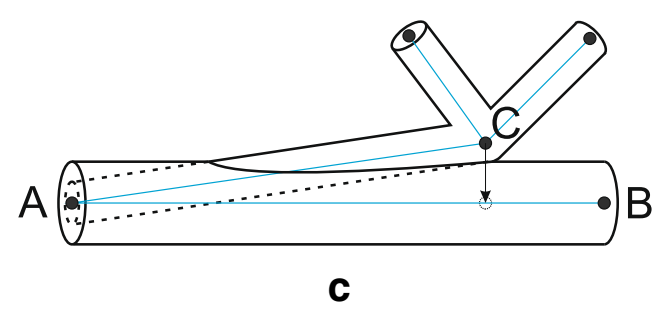

Fig. 3 a Collinear overlapping members, $\mathbf{b}$ chain of members between nodes A and B, c members that overlap significantly

where $i$ and $j$ are the vectors of members $A B$ and $C D$ respectively. Also, $v_{A C}, v_{A D}, v_{C A}$ and $v_{C B}$ are vectors interconnecting the nodes denoted by the given subscript. The members are then split at the nodes they pass through, and overlapping segments deleted.

\subsubsection{Overlapping at nodes}

A pair of members which intersect a common node at a small subtended angle will often overlap over a large part of their length (Fig. 3c). A way of addressing this is to simply merge the two members. Equation (6) determines if the perpendicular distance from one member to the end node of a second member is less than the sum of the radii of the two members. If so, and if the two members are the same length, then the two end nodes are merged and the resulting node placed midway between them. If they have different lengths then the node joined by the shorter element is moved onto the longer element in a direction perpendicular to it. Thus in the case shown in Fig. 3c, node $\mathrm{C}$ would be moved onto element $\mathrm{AB}$, which would then be split into two elements, $\mathrm{AC}$ and $\mathrm{CB}$. This algorithm is performed for all the members at each joint, with the longest member taken as $j$.

$$
\left|j-i\left(\frac{j \cdot i}{|i|^{2}}\right)\right| \leq r_{i}+r_{j}
$$


Considering the example shown in Fig. 3c, $i$ and $j$ would be the vectors of elements $A C$ and $A B$ respectively, which have radii $r_{i}$ and $r_{j}$.

\subsection{Create nodes at intersections}

Layout optimization will frequently generate topologies that include members that crossover one another, presenting two issues: (i) because there is no explicit node at a crossover location (which now forms a joint) the simple buckling analysis that will be presented in Section 3.4 will not provide accurate results; (ii) the joint expansion routine (detailed in Section 3.5) will not be applied at all. The simplest way of addressing both these issues is to find all crossover locations and to then add explicit nodes at these locations, thereby splitting adjoining elements at the newly created node.

Determining which members intersect with one another and the coordinates of the intersection can readily be found. Thus, considering the example depicted in Fig. 4, (7a) and (7b) can be evaluated:

$n_{E i}=n_{A}+i\left[\frac{\left(j \times v_{C A}\right) \cdot(j \times i)}{(j \times i) \cdot(j \times i)}\right]$

$n_{E j}=n_{C}+j\left[\frac{\left(i \times v_{C A}\right) \cdot(j \times i)}{(j \times i) \cdot(j \times i)}\right]$

where $n_{A}$ and $n_{C}$ are the $(x, y, z)$ coordinates of nodes $A$ and $C$ and where $i$ and $j$ are the vectors of elements $A B$ and $C D$. Also, $v_{C A}$ is the vector interconnecting nodes $C$ and $A$ and $n_{E i}$ and $n_{E j}$ are the coordinates of node $E$. If these two coordinates are the same and lie in between nodes $A$ and $B$ for member $i$ and nodes $C$ and $D$ for member $j$ then the members are deemed to crossover. A new node should be created at this location. Calculations of this type should be undertaken for each pair of members in the frame.

\subsection{Sizing optimization}

After modifying the layout of members, a secondary sizing optimization can be performed to update the member crosssectional areas. The same layout optimization formulation

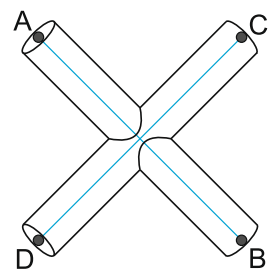

a

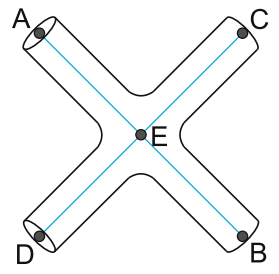

b
Fig. 4 a illustration of two members (AB and $C D$ ) that crossover and b node created at this intersection permitting use of the joint expansion routine detailed in Section 3.5 and design parameters are used, but now using the updated layout as the ground structure. Because the problem size is very small this optimization step adds an insignificant amount of time to the overall post-processing workflow.

\subsection{Resize member areas}

The buckling response of solid circular bars is intrinsically non-linear and thus it is convenient to consider buckling as a post-processing step, rather than during the main optimization phase. The relevant Euler buckling relationship, which must be satisfied for all compressive members, is as follows:

$a_{i} \geq \sqrt{\frac{4 q_{i}^{-}\left(k_{e f f} l_{i}\right)^{2}}{\pi E}} \quad i=1, \ldots, m$

where $a_{i}, q_{i}^{-}$and $l_{i}$ are respectively the area, compressive force and length of member $i$ and $k_{e f f}$ is the effective length factor. Finally, $E$ is the elastic modulus of the material.

Any members that violate this criterion are resized. The choice of a suitable effective length factor $\left(k_{e f f}\right)$ is here investigated experimentally - see Section 4.3.2.

A simple minimum area constraint (9) must also be enforced during the post-processing workflow. This is because many additive manufacturing processes will not effectively capture truss bars below a given diameter.

$a_{i} \geq a_{\min } \quad i=1, \ldots, m$

where $a_{\min }$ is the minimum permitted cross-sectional area.

\subsection{Volume expansion at joints}

Given that numerous elements will often converge at a node in a layout optimization solution, there will often be a significant amount of overlapping in the vicinity of a joint. To avoid high localized stresses at such locations additional material must be introduced. Equation (10) is evaluated at each node to calculate the radius of the joint in proportion

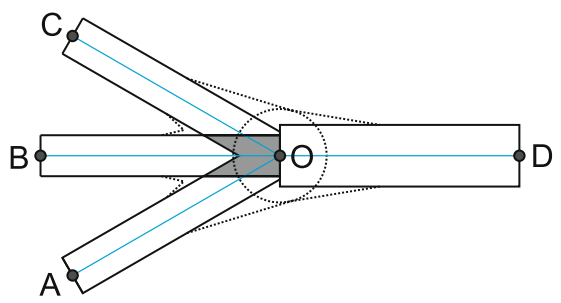

Fig. 5 Schematic of joint expansion 


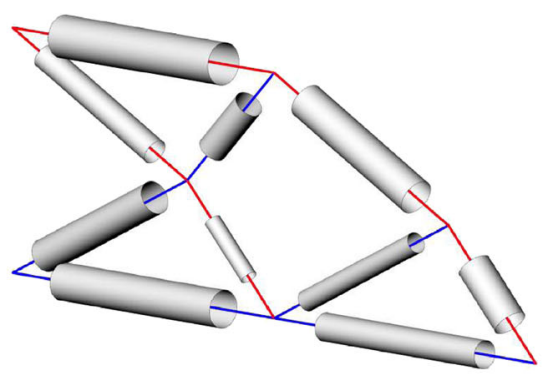

a

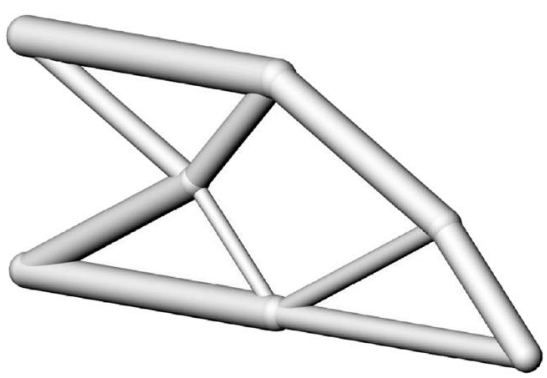

b

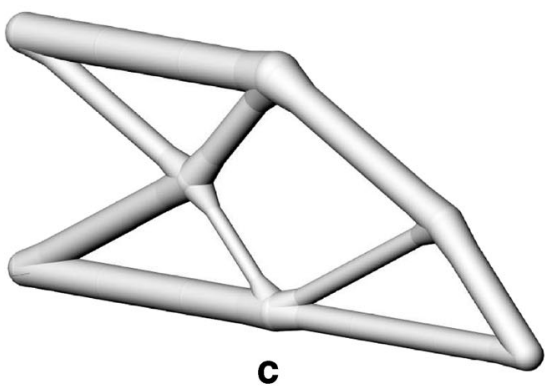

C

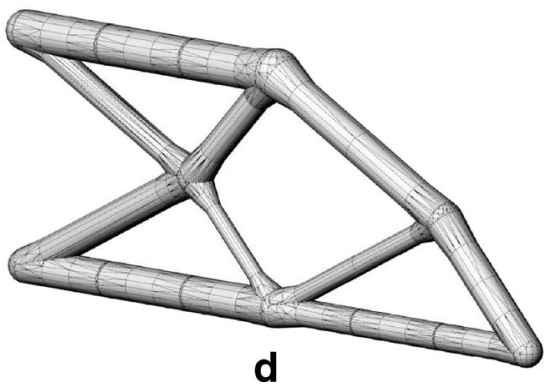

Fig. 6 Steps required to generate an STL mesh model from a line model: a surface lofting; b single solid surface model after Boolean operation; c single surface model with expanded joints; $\mathbf{d}$ conversion to an STL mesh model

to the area and the number and orientation of the elements connected to the node.

$r=\sqrt{\frac{1}{\pi}\left(a_{i}+\sum_{k=1}^{m} a_{j, k}\left\{\hat{i} \cdot \hat{j}_{k}\right\}\right)}$

Where the curly brackets in equation (10) are Macaulay brackets, and where $\hat{i}$ and $a_{i}$ is the unit vector and area of the master member respectively, and $\hat{j}_{k}=\left\{j_{1}, j_{2}, \ldots j_{m}\right\}$ and $a_{j, k}=\left\{a_{j, 1}, a_{j, 2}, \ldots a_{j, m}\right\}$ are the unit vectors and areas of all the other members connected to the node. This equation is evaluated with every member as the 'master' member, with the largest value for the radius being selected.

Note that because additional material is introduced at joints, the volumes of proposed layouts which include large numbers of joints may be significantly increased in this step, potentially rendering the design unviable. In other words, the proposed procedure relies on the initial layout optimization solution being practical, and amenable to postprocessing using the procedure described. If this is not the case the post-processed volume may significantly exceed the reference volume.

\subsection{Solid model generation}

The final form of the component is conveniently generated using Non-Uniform Rational B-Splines (NURBS), which provide a mathematical representation of analytical and free-form geometries and are the industry standard in CAD exchange formats such as STEP and IGES (Piegl and Tiller 1995). Each member is created by extruding a circular cross-section along the length of the line element, with the area being set to that determined from the layout optimization process. At each joint a sphere is created with a radius calculated using (10). At a set distance from the joint node, each truss member is expanded using a linear loft operation so that the end radius is equal to that of the sphere at the joint. This is shown schematically by the dotted line in Fig. 5. Boolean operations are then performed to create a single 'watertight' surface for the whole geometry.

\subsection{Output CAD file}

A STereoLithography (STL) file can then be derived in preparation for additive manufacture and a STEP, IGES or other standard CAD file can be created for input into a commercial finite element analysis package. Here the NURBS

Table 1 Ultimate Tensile Strength (UTS) data of Ti-6Al-4V ELI using the EBM process (Khalid Rafi et al. 2012)

\begin{tabular}{llll}
\hline Build orientation & Finished state & $\begin{array}{l}\text { UTS (MPa) } \\
\text { Mean }\end{array}$ & SD \\
\hline Vertical & Machined & 928 & 9.8 \\
& As built & 842 & 13.8 \\
Horizontal & Machined & 978 & 3.2 \\
& As built & 917 & 30.5 \\
\hline
\end{tabular}

Mean and standard deviation (SD) values are shown 


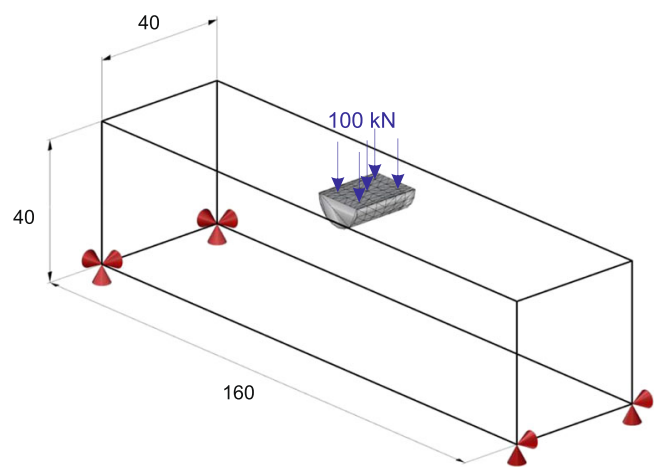

Fig. 7 Example 1: problem definition (all dimensions are in $\mathrm{mm}$ ). Constrained support directions are indicated

based geometries were created using Rhinoceros V5.0 and the Grasshopper plug-in.

Figure 6 shows graphically the main steps required to transform a line model into an STL mesh model ready for additive manufacture.

\section{Component design examples}

The layout optimization workflow outlined in Sections 2 and 3 was applied to two case study problems: a single point loaded beam and an air-brake hinge for the Bloodhound Supersonic Car (SSC) project, with the former being fabricated and load tested.

\subsection{Choice of additive manufacturing process}

Although there are many categories of additive manufacture, the most prevalent type for fabricating geometrically complex components involve the use of a powder-bed. Parts are built from the ground up by depositing thin layers of fine powder $(<100 \mu \mathrm{m}$ thick) and using a laser or electron beam to melt the $2 \mathrm{D}$ cross section in each layer. Generally laser systems have a higher resolution, and yield parts with a better surface finish (Rafi et al. 2013), but suffer from residual stresses as a result of the high cooling rates (Vrancken et al. 2013). Electron beam melting (EBM) on the other hand alleviates these residual stresses by preheating each layer before melting. Also, when melting Titanium Ti-6Al$4 \mathrm{~V}$, the anisotropic mechanical properties associated with the growth of columnar grains during solidification, as seen with other metals when additively manufactured, is largely avoided. This is because Ti-6Al-4V experiences a phase change upon cooling (at $882.5^{\circ} \mathrm{C}$ ), where the large vertically aligned columnar grains transform into a fine, basketweave like microstructure, known as the Widmanstatten microstructure (Al-Bermani et al. 2010). Ti-6Al-4V also has a near perfectly plastic response (Rafi et al. 2013), making it very suitable for use in conjunction with the suggested plastic optimization formulation (see Section 2.1). Polymer materials such as Nylon-12 can also be used but the material properties are very sensitive to process parameters and can be inconsistent between builds and machines (Vasquez et al. 2011; Zarringhalam et al. 2006).

As Ti-6Al-4V parts made from EBM seem to have consistent and near isotropic properties it would appear to be the ideal material to be used for fabricating optimized components, which can then be load tested.

\subsection{Material properties}

As all specimens were to be tested in their as-built state (i.e. with no surface finishing), it is important to distinguish between the mechanical properties of as-built and machine finished Ti-6Al-4V from the EBM process. Ti$6 \mathrm{Al}-4 \mathrm{~V}$ 'extra low interstitials' (ELI) powder was used for

Table 2 Example 1: Volumes of line models resulting from layout optimization with differing nodal densities. (Volumes after the members have been resized to account for buckling are shown for different assumed end conditions)

\begin{tabular}{|c|c|c|c|c|c|c|c|c|c|c|}
\hline \multirow{3}{*}{$\begin{array}{l}\text { Nodal } \\
\text { spacing } \\
(\mathrm{mm})\end{array}$} & \multirow{3}{*}{$\begin{array}{l}\text { No. of } \\
\text { nodes * }\end{array}$} & \multirow{3}{*}{$\begin{array}{l}\text { No. of potential } \\
\text { members }\end{array}$} & \multirow{3}{*}{$\begin{array}{l}\text { Vol. } \\
\left(\mathrm{cm}^{3}\right)\end{array}$} & \multirow[b]{3}{*}{$\Delta \%$} & \multicolumn{6}{|c|}{ Vol. after member resizing } \\
\hline & & & & & \multicolumn{2}{|c|}{ A: Fixed-Fixed } & \multicolumn{2}{|c|}{ B: Fixed-Pinned } & \multicolumn{2}{|c|}{ C: Pinned-Pinnec } \\
\hline & & & & & $\left(\mathrm{cm}^{3}\right)$ & $\Delta \%$ & $\left(\mathrm{~cm}^{3}\right)$ & $\Delta \%$ & $\left(\mathrm{~cm}^{3}\right)$ & $\Delta \%$ \\
\hline- & 8 & 68,724 & 38.1 & 15.2 & 38.1 & 15.2 & 38.1 & 15.2 & 38.76 & 17.2 \\
\hline 20 & 81 & 89,096 & 35.5 & 7.4 & 35.6 & 7.7 & 36.07 & 9.1 & 36.98 & 11.9 \\
\hline 8 & 756 & 499,213 & 34.17 & 3.4 & 37.9 & 14.6 & 39.55 & 19.6 & 43.48 & 31.5 \\
\hline 4 & 4961 & $11,541,432$ & 33.61 & 1.7 & & & & & & \\
\hline 2 & 35721 & $530,708,402$ & 33.32 & 0.8 & & & not res & & & \\
\hline$\infty$ & - & - & $33.06^{* *}$ & 0.0 & & & & & & \\
\hline
\end{tabular}

\footnotetext{
* Excluding nodes in the rigid shell structure (266 in total)

** Reference solution, obtained via extrapolation
} 


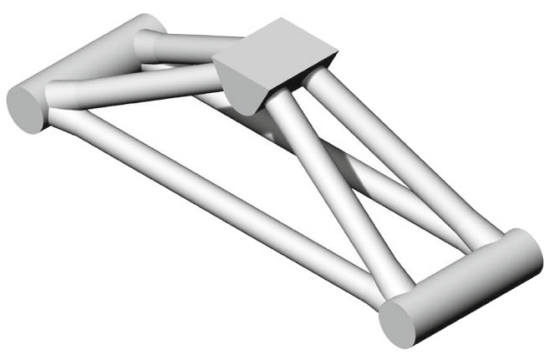

a

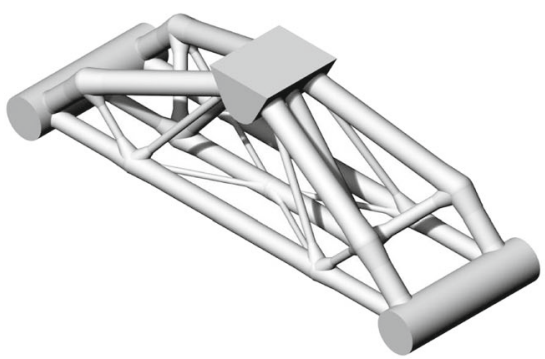

b

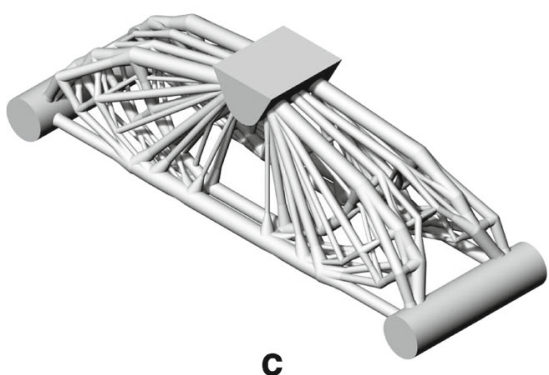

C

Fig. 8 Example 1: candidate designs, a benchmark, $\mathbf{b}$ obtained using a nodal spacing of $20 \mathrm{~mm}$ (89096 potential members), and $\mathbf{c}$ obtained using a nodal spacing of $8 \mathrm{~mm}$ (499213 potential members)

fabricating the specimens. Much of the data available from the machine manufacturer (Arcam) and from the literature for this powder was obtained using specimens that have been machined prior to testing. However one study compared the mechanical properties of machined and as-built tensile specimens and found there to be a significant difference in the ultimate tensile strength (UTS) (Khalid Rafi et al. 2012). These values are shown in Table 1. As all specimens in this study were to be built vertically a value of 842 MPa was selected as the limiting stress in the optimizations. An elastic modulus of $113.8 \mathrm{GPa}$ (standard for Ti-6Al-4V) was used in the subsequent buckling analyses.

\subsection{Example 1: beam subject to point load}

The Messerschmitt-Bölkow-Blohm (MBB) beam is a 2D benchmark optimization problem often referred to in the literature, consisting of two simple supports and an elevated load applied at a location midway between the supports.
To better assess the capabilities of the layout optimization method, this standard problem has been adapted to $3 \mathrm{D}$, as illustrated in Fig. 7.

\subsubsection{Problem definition}

The problem definition shown in Fig. 7 consists of a cuboidal domain with four support locations at the corners of the base. A half-cylindrical rigid shell structure (radius = $7.5 \mathrm{~mm}$ and length $=20 \mathrm{~mm}$ ) discretized using 266 triangular elements is located centrally in the design domain but with the flat surface coplanar with the top surface of the design domain. Each of these triangular elements could accept multiple truss connections. The $100 \mathrm{kN}$ load was applied as a pressure on the flat surface of the rigid shell structure.

This arrangement meant that, even when a single load case was involved, the probability of encountering a solution that was in unstable equilibrium with the applied loading was low. This avoided the need to consider multiple load cases (or the use of a stability formulation, such as the one described by Tyas et al. (2005)) in this preliminary study.

Nodes used for the layout optimization were generated spatially in the design domain using cubic grids of various densities. These nodes, together with those positioned on each triangle forming the rigid shell structure, were used to create the ground structure for each optimization.

\subsubsection{Design candidates}

Volumes from optimizations performed with cubic nodal grids of differing densities were established, a selection of which are shown in Table 2. From these a reference volume $V_{0}$ of $33.06 \mathrm{~cm}^{3}$ was determined, using the power law
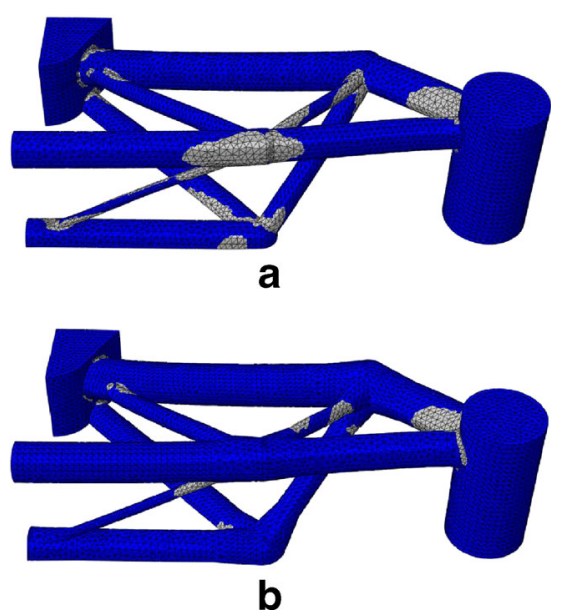

Fig. 9 Example 1: a elasto-plastic finite element analysis of the fixedpinned optimized specimen without joint expansion, and $\mathbf{b}$ with joint expansion. Highlighted are the regions of plastic strain at $80 \%$ of the design load $(80 \mathrm{kN})$ 


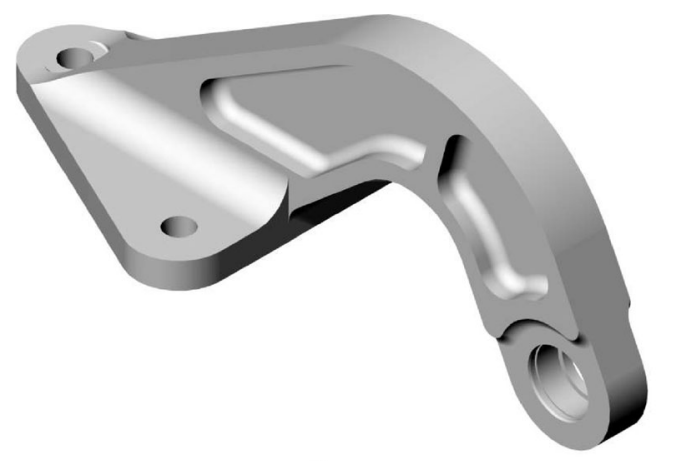

a

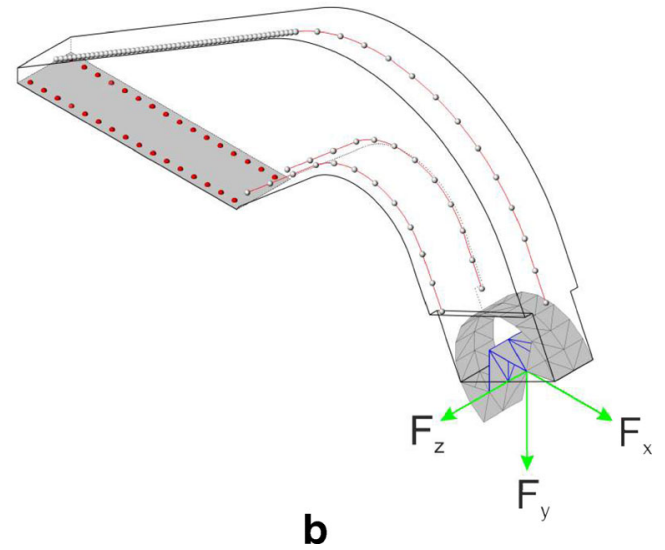

Fig. 10 Example 2: a original air-brake hinge design and b problem definition for the present study, derived from (a)

extrapolation scheme described by Darwich et al. (2010). (Note that this implicitly assumes that a truss form will be optimal, or near-optimal.)

After resizing members for buckling and minimum area considerations, the solutions obtained when using an initially coarse nodal discretization (8 nodal divisions across the span length) were found to lie within approximately 10 $\%$ of the reference volume. In contrast solutions obtained when using more nodes (e.g. 20 nodal divisions) were found to be heavier after member resizing, and considerably more complex (e.g. see layout shown in Fig. 8c). It was therefore considered that the simpler structure shown in Fig. $8 \mathrm{~b}$ made a more suitable design candidate for this preliminary study.

Table 3 Example 2: Load cases considered for Bloodhound SSC airbrake hinge (prior to FoS of 2.4 being applied)

\begin{tabular}{lll}
\hline Load case & $\mathrm{F}_{x}(\mathrm{~N})$ & $\mathrm{F}_{y}(\mathrm{~N})$ \\
\hline 1 & 7550 & 5500 \\
2 & -2981 & 4171 \\
3 & 765 & 3675 \\
4 & 6399 & 2440 \\
5 & 12272 & -4545 \\
\hline
\end{tabular}

\subsubsection{Final designs}

A total of nine examples of the $20 \mathrm{~mm}$ nodal spacing design (shown in Fig. 8a) were fabricated; three identical specimens (for the purposes of repeatability) for each assumed member end condition shown in Table 2. The main difference between each group is the cross-sectional area of the innermost inclined compressive members, which were deemed susceptible to buckling for all three assumed joint conditions.

Additionally, the simple six element truss design shown in Fig. 8a was also designed to act as a benchmark (first entry in Table 2). Again three specimens of this design were fabricated. Note that for the problem considered the benchmark is actually quite competitive, being less than 10 percent heavier than the optimized design. However, for more complex design problems this difference can be expected to be greater.

\subsection{Finite element analysis verification}

A simplified elasto-plastic finite element analysis was performed for the 'fixed-pinned' optimized geometry with and without the joints expanded (see Section 3.5). The specimens with and without expansion at the joints were respectively meshed using 89138 and 104494 10-noded tetrahedral elements, as shown in Fig. 9a and b; in both cases quarter symmetry was assumed. At the time of the

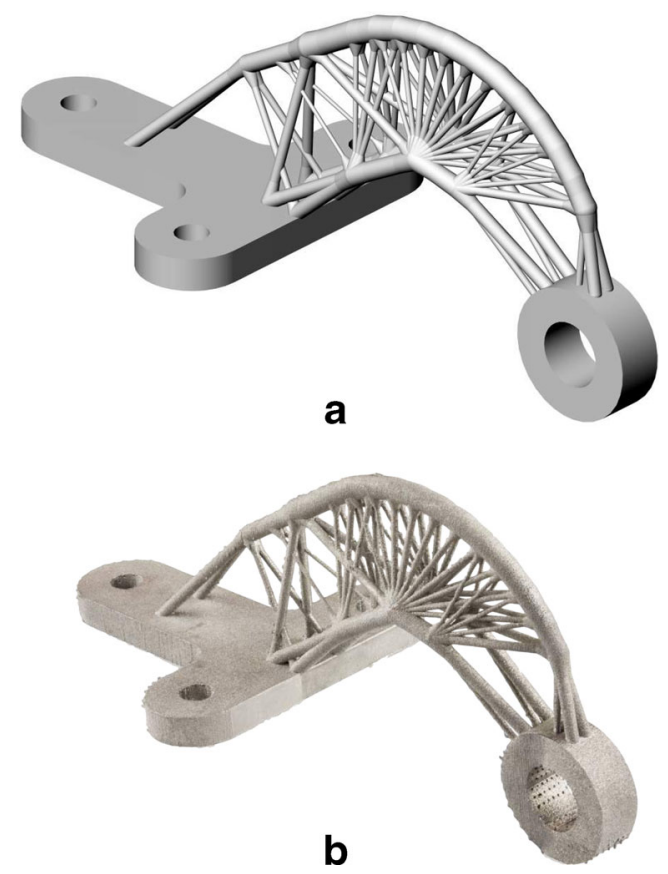

Fig. 11 Example 2: a final design for airbrake hinge (volume = 163.9 $\mathrm{cm}^{3}$ ), b final design additively manufactured from Ti-6Al-4V using the EBM process 
Table 4 Example 2: optimization performed using cubic nodal grids of varying densities. The entry marked with a $(*)$ is the final design produced using a nodal distribution created with the parametric model.
A fixed-pinned end condition assumption was used for the buckling analysis during post-processing

\begin{tabular}{|c|c|c|c|c|c|c|}
\hline \multirow[t]{2}{*}{ Nodal spacing } & \multirow[t]{2}{*}{ No. of nodes } & \multirow[t]{2}{*}{ No. of potential members } & \multicolumn{2}{|l|}{ Vol. } & \multicolumn{2}{|c|}{ Vol. after member resizing } \\
\hline & & & $\left(\mathrm{cm}^{3}\right)$ & $\Delta \%$ & $\left(\mathrm{~cm}^{3}\right)$ & $\Delta \%$ \\
\hline Parametric* & 157 & 13,994 & 34.00 & 13.8 & 35.21 & 17.9 \\
\hline 12.5 & 340 & 36,824 & 33.64 & 12.6 & 34.81 & 16.5 \\
\hline 5 & 1022 & $2,988,133$ & 31.37 & 5.0 & & \\
\hline 3.5 & 8420 & $21,720,412$ & 30.80 & 3.1 & not resized & \\
\hline$\infty$ & - & - & $29.87^{* *}$ & 0.0 & & \\
\hline
\end{tabular}

** Reference solution, obtained via extrapolation

study strain hardening data was not available for as-built titanium manufactured using the EBM process. Thus an elastic-perfectly plastic model was assumed, with an elastic modulus of $113.8 \mathrm{GPa}$, yield stress of $842 \mathrm{MPa}$ and Poisson's ratio of 0.342. It is evident from Fig. 9a and $\mathrm{b}$ that stress concentrations at the joints were reduced by using the joint expansion algorithm, though not entirely eliminated.

\subsection{Example 2: Bloodhound SSC air-brake hinge}

The Bloodhound project aims to build a supersonic car that will break the land speed record, and also reach the landmark top speed of $1000 \mathrm{mph}(1600 \mathrm{~km} / \mathrm{h})$. The predominant braking system is in the form of two deployable air-brakes positioned on each side of the car. Each air-brake is attached to the car with four hinges, as shown in Fig. 10a. The load exerted on each hinge is related to the aerodynamic drag experienced by the air-brake during deployment. Naturally the Bloodhound team wish to keep the structural weight of the car to a minimum and are thus investigating the use of optimization to reduce the mass of this and other components. This provides an opportunity to apply layout optimization to a practical engineering problem.

\subsubsection{Problem definition}

The original design and load cases (Table 3) were provided by the Bloodhound team. The design domain shown in Fig. 10b is based on the topology of the original design. The size of the slot into which the hinge retracts is based on the original design; it is imperative that no material is placed outside the volume of the original design. The volume of the original design in the region to be optimized is $189 \mathrm{~cm}^{3}$. The hinge is subjected to five load cases, derived from various stages in deploying the air-brake (Table 3).
The Bloodhound team require the hinge to resist the loads shown in Table 3 without yielding or failure. A factor of safety (FoS) of 2.4 was therefore specified, to be applied to the loads listed in Table 3.

The initial optimizations were performed using a regular cubic nodal grid, as used for Example 1. Potential members created between these nodes that crossed any of the design domain boundaries (Fig. 10b) were omitted from the ground structure. Nodes shown on the shaded plane in Fig. 10b were subject to a displacement constraint in all three Cartesian directions. A rigid shell structure composed of 78 triangular elements was placed at the tip to represent the connector ring (outer diameter $=50 \mathrm{~mm}$; inner diameter $=24.5 \mathrm{~mm}$ ). Loads were applied directly to the shell structure, on the shell elements shown in Fig. 10b.

From a practical design and manufacturing perspective, the use of a cubic nodal grid proved to be problematic. This is because the resulting topologies generally had numerous members, many of which were very thin. To determine a more appropriate nodal distribution a parametric model was created that would allow nodal locations to be modified in a straightforward manner. The parametric model creates splines that follow the profile of the design domain (illustrated in Fig. 10b). The number and relative spacing of these splines could be defined across the breath and height of the design domain. Nodes could then be created along these splines at a specified spacing. Although this approach is devised based on engineering judgement, a safeguard is

Table 5 Example 1: design and measured masses of the benchmark and 'fixed-fixed' optimized designs

\begin{tabular}{llll}
\hline Sample & $\begin{array}{l}\text { STL } \\
\text { mass } \\
(\mathrm{g})\end{array}$ & $\begin{array}{l}\text { Measured } \\
\text { mass } \\
(\mathrm{g})\end{array}$ & $\Delta \%$ \\
\hline Benchmark & 284.5 & 269.2 & 5.4 \\
Optimized & 273.6 & 259.8 & 5.0 \\
\hline
\end{tabular}


that the resulting volume can always be compared with the reference volume.

After a number of iterations, involving varying the nodal distribution using the parametric model, a final design was arrived upon, as shown in Fig. 11a. The resulting volume was somewhat higher than the reference volume obtained via extrapolation (using increasingly fine nodal discretizations and the extrapolation scheme described by Darwich et al. (2010)); respectively $13.8 \%$ and $17.9 \%$ heavier before and after member resizing, as indicated on Table 4. However, this was nevertheless deemed reasonable.

\section{Additive manufacture and load testing of components}

\subsection{Manufacture}

All specimens were manufactured from gas atomized Ti6Al-4V powder using an Arcam EBM S12 system. Layers were deposited at a thickness $70 \mu \mathrm{m}$ and the standard Arcam Ti-6Al-4V melt, wafer support and preheat themes for were used. In addition to the standard process themes a modified pin support theme based on the standard 'Nett' theme was used to produce porous pin supports.

\subsubsection{Initial build study}

In order to determine how accurately the EBM process would fabricate the two beam designs a preliminary build

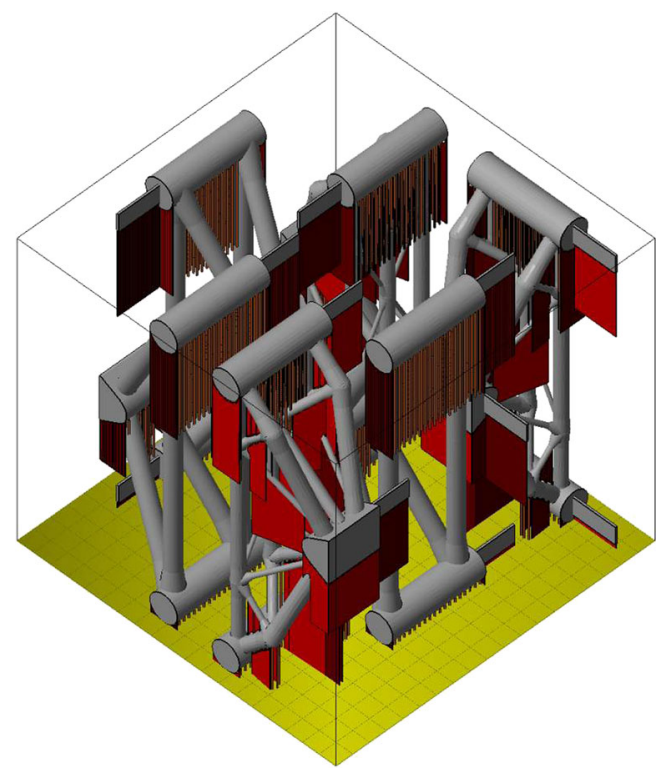

Fig. 12 Example 1: arrangement of specimens during manufacture. The wafer and pin supports structures required by the EBM process to alleviate heat accumulation are shown in red. The build envelope is $190 \times 190 \times 180 \mathrm{~mm}$ study was carried out. The Example 1 benchmark and fixed-fixed optimized designs were fabricated in the same build with the mass and truss member diameters measured upon completion. The mass of each specimen was found to be approximately $5 \%$ lighter than the predicted mass of the STL definitions they were built from (shown in Table 5). The measured truss member diameters were also below those defined in the respective STL files. This discrepancy has been documented previously when using the EBM process to fabricate truss structures (Cansizoglu et al. 2008). As the lengths of the truss members are dimensionally correct, it would seem that the 5 $\%$ volume reduction is the result of undersized truss members areas. Therefore a pragmatic solution to this was to increase the member cross-sectional areas by $5 \%$. (The underlying cause of the issue is quite complex; developing scaling factors more representative of this particular process is beyond the scope of the present study. For a more in-depth study of this issue readers are referred to Smith et al. (2016).)

\subsection{Example 1: beam subject to point load}

\subsubsection{Fabrication}

After the preliminary build study all 12 specimens (incorporating a 1.05 area scale factor) were built in two batches. The specimen arrangement and the support structures utilized for the builds is shown in Fig. 12. Each build took 40 hours to complete on an Arcam S12 machine.

Standard scaling factors were also applied to the whole sample geometry, as prescribed by the manufacturer Arcam (1.0068 in $\mathrm{x}$ - and $\mathrm{y}$-directions and 1.0093 in the $\mathrm{z}$-direction). These account for shrinkage during cooling.

\subsubsection{Load testing arrangement}

All the fabricated specimens were load tested using a universal testing machine in the arrangement shown in Fig. 13.

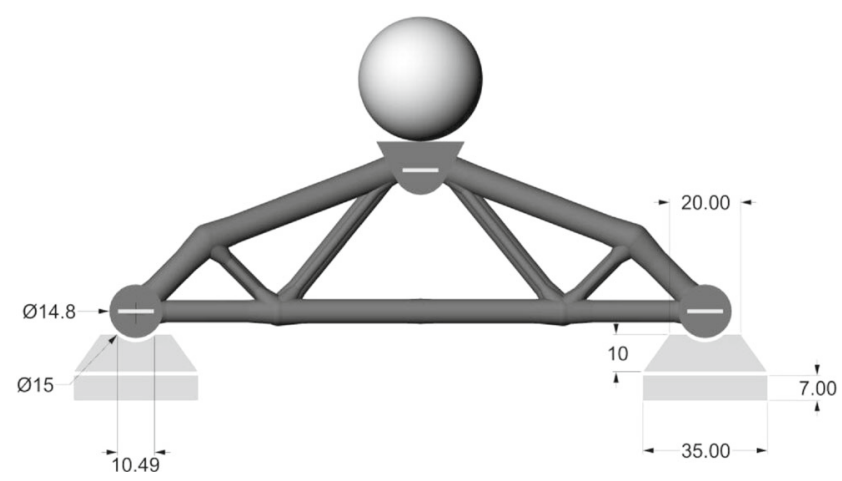

Fig. 13 Example 1: load testing arrangement. (All dimensions are in $\mathrm{mm}$; the three horizontal tabs (shown in white) are for LVDT gauges) 


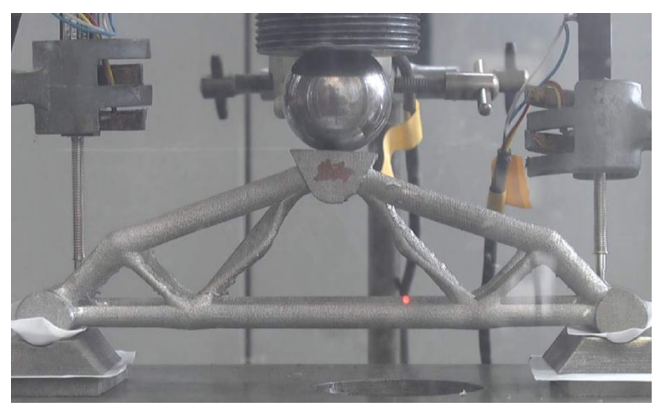

Fig. 14 Example 1: specimen A1 at ultimate load. The specimen failed through the buckling of the four central compressive members

Each specimen was placed on two sets of supporting blocks, each set having one grooved and one flat support. All contact surfaces were polished and lined with PTFE sheets. The grooved support provided more contact surface with the cylindrical ends of the specimens, helping distribute the reaction load whist allowing rotation. The flat support permits the grooved support to translate horizontally with minimal resistance, effectively replicating a roller support. The load was applied centrally on each specimen using a polished steel ball coupled to the ram of the testing machine. The ram applied the load at a constant displacement rate of $2.78 \times 10^{-3} \mathrm{~mm} / \mathrm{s}$ (Fig. 14).

\subsubsection{Load testing results}

The measured masses and results from the load tests for all twelve specimens are shown in Table 6. The speci- mens designated by ' $\mathrm{O}$ ' are the benchmark designs and the load-displacement curves for these specimens are shown in Fig. 15 (it is evident that all the specimens narrowly failed to carry the design load of $100 \mathrm{kN}$ ). The optimized specimens, designated A, B and C are those analysed assuming fixed-fixed, fixed-pinned and pinned-pinned end conditions respectively in the buckling analysis. The load displacement curves for these specimens are shown in Fig. 16.

It is evident that most of the specimens designated B and $\mathrm{C}$ were able to carry the design load of $100 \mathrm{kN}$, whereas, as expected, specimens designated A did not.

\subsection{Example 2: Bloodhound SSC air-brake hinge}

\subsubsection{Fabrication of Bloodhound SSC air-brake hinge}

To demonstrate the design could be realised physically, the Bloodhound SSC air-brake hinge was also fabricated, using the same approach as used for the beam specimens. The fabricated design is shown in Fig. 11b.

The volume and mass of the solid model and fabricated component are shown in Table 7. The volume of the original design replaced by the truss structure was $189 \mathrm{~cm}^{3}$. However, as the original part was designed to be fabricated using aluminium $7075 \mathrm{~T} 7$ alloy rather than titanium Ti$6 \mathrm{Al}-4 \mathrm{~V}$, this volume should be scaled to obtain the volume which would be occupied by a structurally equivalent titanium component (i.e. scaling by the ratio of the ultimate strengths of aluminium $7075 \mathrm{~T} 7$ alloy and titanium Ti-6Al$4 \mathrm{~V}, 505 \mathrm{MPa}$ and $842 \mathrm{MPa}$ respectively). This gives a scaled

Table 6 Example 1: volume, mass and load test results for all the fabricated beam specimens

\begin{tabular}{|c|c|c|c|c|c|c|c|}
\hline \multirow[t]{2}{*}{ Specimen } & \multirow{2}{*}{$\begin{array}{l}\text { Line model } \\
\text { (resized members) } \\
\text { volume } \\
\left(\mathrm{cm}^{3}\right)\end{array}$} & \multicolumn{2}{|l|}{$\begin{array}{l}\text { Solid model } \\
\text { (truss only) }\end{array}$} & \multirow[t]{2}{*}{$\begin{array}{l}\text { Solid model } \\
(\text { total mass *) } \\
(\mathrm{g})\end{array}$} & \multirow[t]{2}{*}{$\begin{array}{l}\text { Fabricated } \\
\text { Mass } \\
(\mathrm{g})\end{array}$} & \multirow[t]{2}{*}{$\begin{array}{l}\text { Ultimate } \\
\text { load } \\
(\mathrm{kN})\end{array}$} & \multirow[t]{2}{*}{$\begin{array}{l}\text { Strength to } \\
\text { weight ** } \\
(\mathrm{kN} / \mathrm{g})\end{array}$} \\
\hline & & Volume $\left(\mathrm{cm}^{3}\right)$ & Mass (g) & & & & \\
\hline $\mathrm{O} 1$ & & & & & 284.6 & 85.9 & \\
\hline $\mathrm{O} 2$ & 38.10 & 41.15 & 182.3 & 284.5 & 283.2 & 91.6 & 0.499 \\
\hline $\mathrm{O} 3$ & & & & & 281.8 & 95.3 & \\
\hline $\mathrm{A} 1$ & & & & & 273.4 & 81.6 & \\
\hline $\mathrm{A} 2$ & 35.60 & 38.06 & 168.6 & 273.6 & 268.8 & 80.3 & 0.477 \\
\hline A 3 & & & & & 269.4 & 79.4 & \\
\hline B1 & & & & & 260.2 & 93.2 & \\
\hline B2 & 36.07 & 38.24 & 169.4 & 266.8 & 258.8 & 102.4 & 0.583 \\
\hline B3 & & & & & 258.6 & 100.9 & \\
\hline $\mathrm{C} 1$ & & & & & 260.6 & 101.7 & \\
\hline $\mathrm{C} 2$ & 36.98 & 39.20 & 173.7 & 270.0 & 262.8 & 98.6 & 0.590 \\
\hline $\mathrm{C} 3$ & & & & & 262.4 & 107.2 & \\
\hline
\end{tabular}

\footnotetext{
* Total mass is the truss mass plus that of the ancillary structural elements required for load testing

** Strength-to-weight is based on the truss only mass
} 


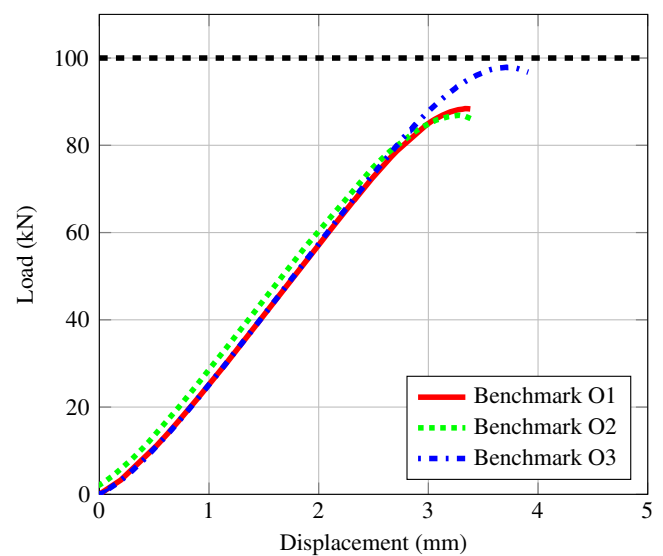

Fig. 15 Example 1: Load-Displacement curves for benchmark samples (O1 - O3)

volume of $113 \mathrm{~cm}^{3}$. With a volume of $35.27 \mathrm{~cm}^{3}$, the truss structure therefore consumes $69 \%$ less material compared with the original component.

\section{Discussion}

\subsection{Optimization methodology}

This study has demonstrated that layout optimization can be used as a part of a workflow to automatically produce 3D CAD models, ready for additive manufacture. Physical load testing of beam specimens designed using this workflow, and then fabricated using the EBM process, generally met or slightly exceeded the required load capacity. The beam problem was selected for its simplicity for this exploratory study and as such the potential for mass reduction was limited (approx. $7 \%$ compared with the benchmark design in this case). The difference in the measured strength-toweight ratio of the benchmark and optimized specimens was a more significant $18 \%$ increase in the case of the latter. For the more complex Bloodhound SSC airbrake hinge problem the volume reduction was however much more significant (approx. $69 \%$ ).

It is clearly imperative to properly account for buckling in the proposed workflow. When checking the optimized designs, the specimens designed assuming 'fixed-pinned' and 'pinned-pinned' end support conditions in the buckling calculations generally met or slightly exceeded the design load. Those designed using the 'fixed-fixed' assumption (samples A1-3) failed through buckling at around $80 \%$ of the design load, with the buckling failure of specimen A2 shown in Fig. 14. This might suggest that at least the 'fixedpinned' end support condition should be used in future

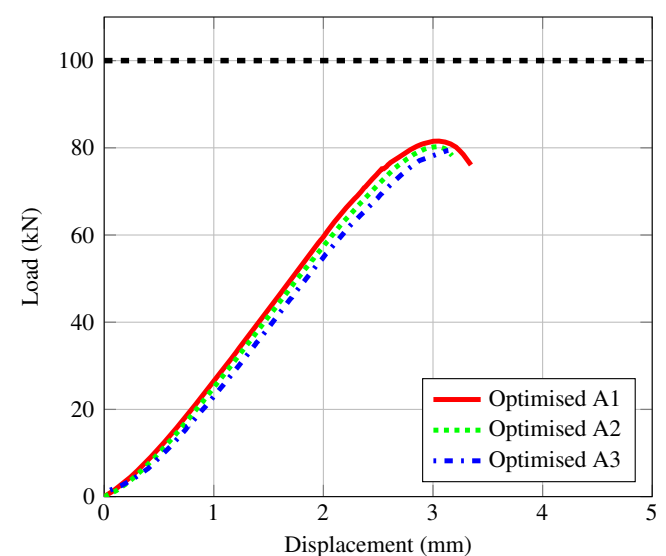

a

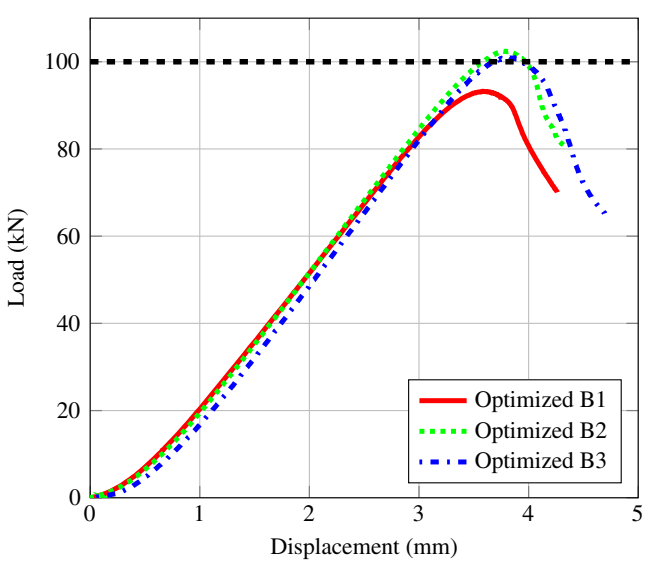

b

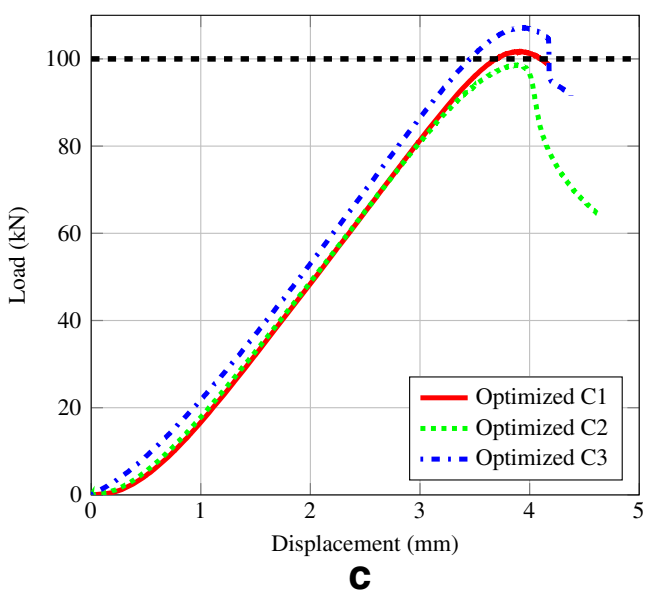

Fig. 16 Example 1: load-displacement curves for samples a A1-3 (fixed-fixed), b B1-3 (fixed-pinned) and c C1-3 (pinned-pinned)

when considering buckling. However, all three of the benchmark specimens (i.e. samples O1-3) which were analysed using the 'fixed-pinned' end conditions failed through buckling at approx. $91 \%$ of the design load. This indicates that more a rigorous frame buckling instability analysis should in future be undertaken. 
Table 7 Example 2: Volume and mass data of final Bloodhound SSC air-brake hinge design

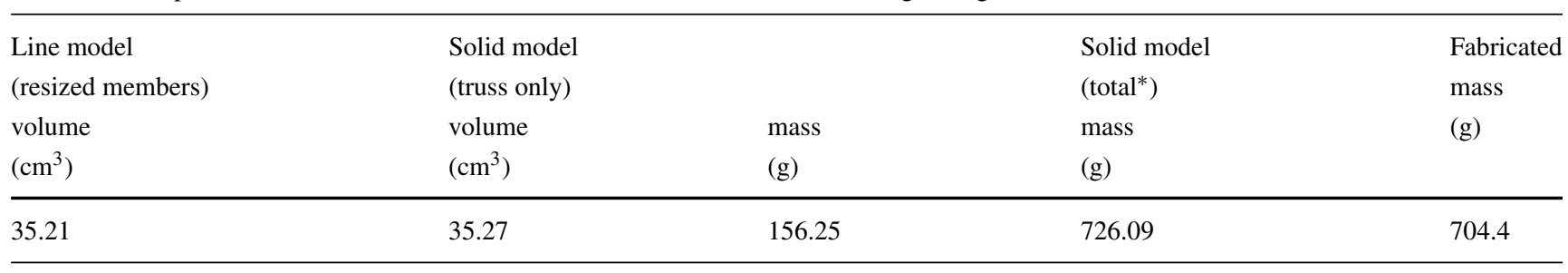

* Total mass is the truss mass plus the plate and ring structure which were not included as part of the optimization

When increasingly fine nodal discretizations are used, layout optimization can be used to provide an estimate of the likely mathematical optimum solution, with this then providing a reference volume $\left(V_{0}\right)$ for future design studies. However, there is a need to identify design solutions which are more practical (i.e. which do not contain numerous thin members, which are difficult to manufacture using additive manufacturing techniques and/or which are susceptible to buckling). This can be achieved by ensuring the optimization formulation includes appropriate manufacturability and/or buckling constraints. Alternatively, as in this study, coarse nodal discretizations can be used to obtain simpler design solutions, with checks then performed retrospectively. Provided the volume of the resulting component is within an acceptable of margin of the reference volume then this, or indeed any other strategy, can be justified. The main drawback of the strategy adopted here is that some iterations were required in order to obtain a viable design solution. However, the need for iteration could potentially be reduced through the use of a geometry optimization rationalization step (this involves adjusting the positions of nodes, which in turn leads to removal of many thin elements (He and Gilbert 2015). This could potentially replace the sizing optimization step described in Section 3.3.

The present study made use of solid circular crosssections to keep the solid model generation and fabrication stages as straightforward as possible. However, in future the use of more structurally efficient cross-sections could be used (e.g. cruciform sections, which are more buckling resistant). This will often mean that the volume does not increase following the main optimization.

The finite element analysis highlighted that stress concentrations will occur at the joints if material is not added to compensate for overlapping elements, as expected. The simple volume expansion algorithm used in this study did successfully address this problem, though a more rigorous volume conservation algorithm could be applied at the joints, potentially reducing the volume of material added in this step.
Although the workflow presented here is comparatively simple, the results from the beam load tests, and the significant mass reduction achieved in the case of the Bloodhound SSC airbrake hinge, serve to demonstrate the potential of the method. A key potential benefit of the method is that the process of transforming the optimization result into a feasible CAD model is simpler than when using many existing continuum based methods (these methods often require significant manual interpretation and/or post-processing to produce a feasible design, with smooth and well defined surfaces).

\subsection{Additive manufacturing}

As mentioned earlier, a scaling factor of 1.05 was applied to all element areas of each specimen to compensate for an issue with the EBM process which led to many of the truss members in the fabricated specimens being undersized. This scaling factor was, however, applied globally, whereas the degree to which the truss members were undersized was found to vary locally. For example, only truss members not aligned to the build direction (i.e. not vertical) appeared to be affected and the general trend was that members with a greater angle to the build direction were affected more. However, rather than developing more specific scaling factors, it is probably more worthwhile to develop more robust EBM process themes, tailored for truss type structures.

\section{Conclusions}

- A workflow in which layout optimization is used to automatically design components suitable for fabrication via additive manufacture has been developed.

- Beam specimens designed using the proposed workflow, and fabricated using titanium Ti-6Al-4V, generally met or slightly exceeded the target design load capacity.

- A reference volume, derived by performing a series of increasingly fine resolution layout optimization runs, was used to quantify the structural efficiency of the 
components produced. The two designed components were at least $80 \%$ efficient (i.e. were within $20 \%$ of their respective reference volumes).

- The volumes of the designed components were also compared with those of simpler benchmark components, of the sort that would be designed by manual means. Although the volume of the optimized beam was just $7 \%$ lower than the benchmark, the optimized Bloodhound SSC airbrake hinge component was a far more significant $69 \%$ lower than the benchmark. This highlights the potential for applying the proposed workflow to real-world engineering problems.

- The workflow lays a foundation on which further developments can be made. Potential extensions, which should result in greater mass reduction, and/or less need for manual intervention by the user, have been outlined.

- Whilst the Electron Beam Melting (EBM) additive manufacture process employed was successfully able to fabricate all the designs described, various dimensional accuracy issues were encountered which need to be addressed in the future.

Acknowledgments The first author acknowledges the sponsorship of the Advanced Metallic Systems Centre for Doctoral Training, an EPSRC funded centre involving the Universities of Sheffield and Manchester.

Open Access This article is distributed under the terms of the Creative Commons Attribution 4.0 International License (http:// creativecommons.org/licenses/by/4.0/), which permits unrestricted use, distribution, and reproduction in any medium, provided you give appropriate credit to the original author(s) and the source, provide a link to the Creative Commons license, and indicate if changes were made.

\section{References}

Aage N, Nobel-Jørgensen M, Andreasen CS, Sigmund O (2013) Interactive topology optimization on hand-held devices. Struct Multidiscip Optim 47(1):1-6

Al-Bermani SS, Blackmore ML, Zhang W, Todd I (2010) The Origin of Microstructural Diversity, Texture, and Mechanical Properties in Electron Beam Melted Ti-6Al-4V. Metall Mater Trans A 41(13):3422-3434. doi:10.1007/s11661-010-0397-x

Aremu A, Ashcroft I, Hague R, Wildman R, Tuck C (2010) Suitability of SIMP and BESO Topology Optimization Algorithms for Additive Manufacture. In: Twenty First Annual International Solid Freeform Fabrication Symposium, Austin, pp 679-692

Brackett D, Ashcroft I, Hague R (2011) Topology optimisation for additive manufacture. In: Twenty Second Annual International Solid Freeform Fabrication Symposium, Austin, pp 348-362

Cansizoglu O, Harrysson OL, West IIHA, Cormier DR, Mahale T (2008) Applications of structural optimization in direct metal fabrication. Rapid Prototyp J 14(2):114-122. doi:10.1108/13552540810862082

Darwich W, Gilbert M, Tyas A (2010) Optimum structure to carry a uniform load between pinned supports. Struct Multidiscip Optim 42(1):33-42

Deaton JD, Grandhi RV (2014) A survey of structural and multidisciplinary continuum topology optimization: post 2000. Struct Multidiscip Optim 49(1):1-38

Dorn WS, Gomory RE, Greenberg HJ (1964) Automatic design of optimal structures. J Mech 3:25-52

Gilbert M, Tyas A (2003) Layout optimization of largescale pin-jointed frames. Eng Comput 20(8):1044-1064. doi:10.1108/02644400310503017. http://www.ingentaconnect. com/content/mcb/182/2003/00000020/00000008/art00006

Guo X, Zhang W, Zhong W (2014) Doing topology optimization explicitly and geometricallya new moving morphable components based framework. J Appl Mech 081(8):009

He L, Gilbert M (2015) Rationalization of trusses generated via layout optimization. Struct Multidiscip Optim 52(4):677-694. doi:10.1007/s00158-015-1260-x

Khalid Rafi H, Karthik N, Starr TL, Stucker BE (2012) Mechanical property evaluation of Ti-6Al-4V parts made using Electron Beam Melting. In: Twenty Third Annual International Solid Freeform Fabrication Symposium, Austin, pp 526-535

Mosek APS (2014) The MOSEK optimization software. http://www. mosek.com

Pichugin AV, Tyas A, Gilbert M (2012) On the optiMality of hemps arch with vertical hangers. Struct Multidiscip Optim 46(1):17-25

Piegl L, Tiller W (1995) The NURBS Book. Springer, p 1007. http:// link.springer.com/book/10

Pritchard TJ, Gilbert M, Tyas A (2005) Plastic Layout Optimization of Large-Scale Frameworks Subject to Multiple Load Cases, Member Self-Weight and with Joint Length Penalties. In: 6th World Congresses of Structural and Multidisciplinary Optimization. Rio de Janeiro

Rafi HK, Karthik NV, Gong H, Starr TL, Stucker BE (2013) Microstructures and Mechanical Properties of Ti6Al4V Parts Fabricated by Selective Laser Melting and Electron Beam Melting. Materials Engineering and Performance 22(December):38723883, doi:10.1007/s11665-013-0658-0

Rezaie R, Badrossamay M, Ghaie A, Moosavi H (2013) Topology Optimization for Fused Deposition Modeling Process. Proced CIRP 6:522-527. doi:10.1016/j.procir.2013.03.098. http:// linkinghub.elsevier.com/retrieve/pii/S2212827113001728

Rozvany GIN, Sokół T, Pomezanski V (2014) Fundamentals of exact multi-load topology optimization-stress-based least-volume trusses (generalized Michell structures)-part I: Plastic design. Struct Multidiscip Optim 50(6):1051-1078

Rozvany GIN (2009) A critical review of established methods of structural topology optimization. Struct Multidiscip Optim 37(3):217237. doi:10.1007/s00158-007-0217-0

Smith C, Derguti F, Nava EH, Thomas M, Tammas-Williams S, Gulizia S, Fraser D, Todd I (2016) Dimensional accuracy of electron beam melting (ebm) additive manufacture with regard to weight optimized truss structures. J Mater Process Technol 229:128-138

Sokół T, Lewiński T (2010) On the solution of the three forces problem and its application in optimal designing of a class of symmetric plane frameworks of least weight. Struct Multidiscip Optim 42(6):835-853

Tomlin M, Meyer J (2011) Topology Optimization of an Additive Layer Manufactured ( ALM ) Aerospace Part. In: The 7th Altair CAE Technology Conference 2011, Bristol, pp 1-9 
Tyas A, Gilbert M, Pritchard T, Street M (2005) Practical Plastic Layout Optimization of Trusses Incorporating Stability Considerations. In: 6th World Congresses of Structural and Multidisciplinary Optimization, Rio de Janeiro

Vasquez M, Haworth B, Hopkinson N (2011) Optimum sintering region for laser sintered nylon-12. Proc Inst Mech Eng B J Eng Manuf 225:2240-2248. doi:10.1177/0954405411414994

Vrancken B, Wauthle R, Kruth J, Van Humbeeck J (2013) Study of the influence of material properties on residual stress in selective laser melting. In: Twenty Fourth Annual International Solid Freeform Fabrication Symposium, Austin, http://utwired.engr.
utexas.edu/lff/symposium/proceedingsArchive/pubs/Manuscripts/ 2013/2013-31-Vrancken.pdf

Wieloch D, Taslim I (2004) Driving Million Dollar Savings at Ford using Structural Optimisation. In: The Altair Technology Conference, pp 5.1-5.7

Zarringhalam H, Hopkinson N, Kamperman N, De Vlieger J (2006) Effects of processing on microstructure and properties of SLS Nylon 12. Mater Sci Eng A 435-436:172180. doi:10.1016/j.msea.2006.07.084. http://linkinghub.elsevier. com/retrieve/pii/S092150930601478X 